\title{
Clinical recommendations for autologous platelet derivatives used in periodontal regeneration
}

\author{
Recomandări clinice ale derivaţilor plachetari autologi utilizaţi în regenerarea \\ parodontală
}

\author{
Sofia Iozon, Alexandra Roman, Andrada Şoancă \\ Disciplina de Parodontologie, Universitatea de Medicină şi Farmacie \\ „Iuliu Haţieganu“, Cluj-Napoca, România
}

\begin{abstract}
The main goal of periodontal regenerative techiques is to recreate the soft and hard lost tissues for functional and aesthetic reasons. Because of the complexity of this proccess (multiple celular types that need to be stimultated in a particular time sequence for recreation of all four periodontal tissues), periodontal regenerative techniques are still inconsistant and unpredictable. In the last decades, the tendency in surgical periodontal approaches is to use autologous products like platelet concentrates, because of their high content in growth factors that improve the healing proccess and promote tissue regeneration. The existing scientific proofs on this matter are yet insufficient for reliable clinical conclusions upon the use of platelet concentrates in periodontal surgical therapy.
\end{abstract}

Keywords: autologous platelet concentrates, periodontal regeneration, periodontal infrabony defects

\section{REZUMAT}

Scopul tehnicilor regenerative tisulare parodontale este refacerea ţesuturilor moi şi dure pentru integrare funcţională şi estetică. Tehnicile regenerative parodontale sunt la ora actuală imprevizibile din cauza multitudinii de linii celulare care necesită a fi stimulate şi a secvenţelor temporale stricte de derulare a reacţiilor care conduc la refacerea tuturor celor patru țesuturi care compun parodonţiul. În ultimii ani, există tendinţe în chirurgia parodontală de folosire a produselor autologe cum sunt concentratele plachetare, deoarece conţin factori de creştere care îmbunătăţesc vindecarea şi promovează regenerarea tisulară. Dovezile ştiinţifice existente în acest domeniu sunt însă insuficiente pentru trasarea unor concluzii clare cu aplicabilitate clinică în ceea ce priveşte utilitatea acestor preparate în terapia chirurgicală parodontală.

Cuvinte cheie: derivaţi plachetari autologi, regenerare parodontală, defecte parodontale infraosoase

\footnotetext{
Abrevieri

$\mathrm{PRP}=$ platelet-rich plasma $=$ plasmă bogată în plachete sangvine,

$\mathrm{PRF}=$ platelet-rich fibrin = fibrină bogată în plachete sangvine,

RTG = regenerare tisulară ghidată,

PDGF $=$ platelet-derived growth factors $=$ factori de creştere plachetari,

TGF $\beta-1$ = transforming growth factor $\beta-1=$ factorul transformator de creştere $\beta-1$,

VEGF = vascular endothelial growth factor, factor de creştere endotelială vasculară,

$\mathrm{EGF}=$ endothelial growth factor $=$ factor de creştere endotelială,

IGF-1 = insulin-like growth factor-1,

$\mathrm{TCR}=$ trial clinic randomizat,

OFD = open-flap debridement $=$ lambou de asanare,

$\mathrm{BDX}=$ bovine derived xenograft $=$ xenogrefă de origine bovină,

DFDBA = decalcified freeze-dried bone allograft = allogrefă osoasă demineralizată, înghețată şi disecată/liofilizată,

$\mathrm{HA}=$ hidroxiapatită,

beta-TCP $=$ beta-fosfat tricalcic .
} 


\section{INTRODUCERE}

\section{Regenerarea parodontală - mit sau realitate?}

Boala parodontală este o afecțiune frecventă, cu o etiologie complexă. Ea constă în distrucția progresivă a țesuturilor de susţinere ale dintelui. Natura sa infecțioasă-inflamatorie este bine cunoscută (1). Dovezi ştiinţifice şi clinice puternice susțin posibilitatea stopării evoluției bolii. Cel mai adesea, în special în formele incipiente sau moderate de afectare, în urma terapiei cauzale, parodonțiul îşi recapătă statusul sănătos. În cazul formelor severe însă, terapii mai agresive sunt de obicei necesare pentru a compensa efectul pierderii avansate de os şi pentru a îmbunătăți statusul oral. Regenerarea țesuturilor de susţinere pierdute reprezintă scopul final al terapiei parodontale şi, în acelaşi timp, cea mai mare provocare în rândul practicienilor. Literatura de specialitate propune diferite tehnici regenerative, cu sau fără utilizarea biomaterialelor pentru stimulare a potențialului regenerator intrinsec al parodonțiului. Din păcate, rezultatele acestor tehnici sunt inconstante şi imprevizibile (2-5).

Conform Academiei Americane de Parodontologie, regenerarea parodontală este definită ca „reproducerea sau reconstruirea unei părți pierdute sau afectate din parodonțiu, într-o manieră identică sau similară cu țesuturile inițiale“ (American Academy of Periodontology - Glossary of periodontal terms, 1992). Succesul acestui proces este susținut de dovezi histologice asupra formării de os şi cement nou şi de ligamente parodontale orientate funcțional şi inserate în noile țesuturi.

Vindecarea plăgilor rezultate în urma traumei chirurgicale parodontale implică o secvență complexă, ordonată şi elaborată de procese. Acestea au la bază multiple tipuri celulare ghidate de mediatori solubili şi molecule semnal care sunt capabile să direcționeze celulele circulante înspre locul lezat (6). În mod normal, procesele implicate în vindecarea plăgilor se împart în patru etape succesive şi includ hemostaza, inflamația, faza de formare a țesutului de granulație şi remodelarea (7). În final, rezultă vindecarea prin cicatrici sau regenerarea tisulară.

Dificultatea reproducerii etapelor biologice se reflectă în multitudinea de încercări în ceea ce priveşte tehnicile regeneratoare şi în rezultatele inconstante. La ora actuală, diverse modalităţi de trata- ment sunt asociate tehnicilor cu lambou, pentru obținerea regenerării parodontale: substitutele osoase, membranele cu funcție de barieră (RTG), utilizarea factorilor de creştere, tehnici de inginerie tisulară, mediatori biologici sau combinații ale procedurilor menționate. $\mathrm{Cu}$ toată varietatea lor, tratamentul regenerativ ideal cu rezultate predictibile nu a fost găsit (2-5).

În comparație cu lamboul de asanare simplu, utilizarea regenerării tisulare ghidate (cu sau fără substitute osoase) pentru tratamentul defectelor parodontale infraosoase duce la beneficii clinice semnificativ mai mari. S-au obținut rezultate superioare în cazul aplicării RTG: diferențe în câştigul de ataşament între $1,58 \mathrm{~mm}(8)$ şi $0,95 \mathrm{~mm}$ (9), o reducere suplimentară a adâncimii pungilor parodontale de 1,52 mm şi umplere osoasă decelabilă radiologic cu 2,53 mm mai mare. Aceste efecte încurajatoare sunt susţinute şi de dovezi histologice de obținere a regenerării parodontale (10).

Pentru defectele infraosoase conformate (cu 2 sau 3 pereți osoşi), asocierea substitutelor osoase la membrane nu aduce beneficii suplimentare, deci nu este necesară $(8,9)$.

Înțelegerea procesului de vindecare a plăgilor a cunoscut progrese semnificative odată cu identificarea factorilor de creştere şi cu dezvoltarea tehnicilor care permit manipularea acestora. Molecule precum PDGF (platelet-derived growth factor), TGF $\beta$-1 (transforming growth factor $\beta-1$ ), VEGF (vascular endothelial growth factor), EGF (endothelial growth factor) şi IGF-1 (insulin-like growth factor-1) sunt implicate în coordonarea activității celulare pe durata vindecării.

Plachetele sangvine dețin un rol extrem de important în acest proces, prin participarea la hemostază şi prin conținutul mare de factori de creştere. La momentul actual, derivatele plachetare reprezintă agenți biologici promiţători, care pot fi utilizați cu success în parodontologie. În funcție de protocolul de obținere, au fost descrise mai multe variante de concentrate plachetare. $\mathrm{Cu}$ toate că există informații abundente furnizate de reviewurile sistematice şi meta-analizele conduse până acum, nu există concluzii clare asupra beneficiului suplimentar adus de utilizarea acestor preparate în terapia parodontală regeneratoare. De asemenea, există multiple întrebări legate de relevanța clinică (şi nu statistică) a rezultatelor obținute. 
Astfel, lucrarea de față îşi propune să facă o sinteză a informațiilor disponibile în literatură, în ceea ce priveşte efectele biologice şi clinice ale derivatelor plachetare autologe în tehnicile regeneratoare ale defectelor parodontale infraosoase. De asemenea, review-ul dorește să scoată în evidență erorile metodologice care ar putea masca adevăratul potențial regenerativ al preparatelor şi să formuleze câteva concluzii utile pentru practicieni.

\section{Derivatele plachetare autologe - clasificare}

Rolul plachetelor sangvine în procesul de hemostază a fost demonstrat prin evidențierea implicării acestora în etapele de obliterare vasculară şi formare a cheagului de fibrină (6). De asemenea, plachetele sangvine sunt responsabile pentru activarea şi eliberarea unor biomolecule importante: proteine specifice, factori de creştere (PDGF), factori ai coagulării, molecule de adeziune, citokine / chemokine şi factori angiogenici, capabili să stimuleze proliferarea şi activarea celulelor implicate în vindecare (inclusiv fibroblaste, neutrofile, macrofage şi celule stem mezenchimale) (11). Datorită acestor motive, derivatele plachetare au început să fie utilizate în medicina modernă cu mai bine de patru decenii în urmă. Argumentul principal este impactul pe care îl au plachetele sangvine asupra regenerării tisulare (inclusiv parodontale) prin facilitarea angiogenezei şi a altor etape din procesul de vindecare, efecte obținute datorită capacității de recrutare celulară, de stimulare a proliferării, remodelării şi diferențierii.

În funcție de protocolul de preparare, se obțin diverse produse, cu efecte biologice şi aplicații diferite.

a. Platelet-rich plasma (plasmă bogată în plachete sangvine - PRP) este considerat concentrat plachetar de primă generație. Sângele pacientului este recoltat împreună cu o substanță anticoagulantă şi apoi centrifugat conform unor protocoale. Produsul final este în formă lichidă sau are consistență de gel. Este necesară adăugarea de substanțe suplimentare (trombină de origine bovină şi/sau clorură de calciu) pentru activarea plachetelor şi formarea rețelei de fibrină (12). Cercetările au arătat că PRP eliberează factori de creştere pe o perioadă de până la 7 zile, iar cantităţile cele mai mari (aproape întreaga rezervă de factori de creştere conţinuți) sunt eliberate în prima zi după aplicare (12).
Pentru obținerea PRP sunt necesare două cicluri de centrifugare. În primă etapă, celulele roşii sunt separate de plasmă şi de stratul leuco-trombocitar (13). În cea de-a doua fază, PRP este obținut prin separarea concentratului plachetar de plasma săracă în plachete. Se obține astfel o concentrație de 6-8 ori mai mare în trombocite, față de sângele integral (14). Regenerarea tisulară este facilitată de nivelurile înalte de molecule bioactive eliberate de plachetele sangvine în micro-mediul înconjurător (15).

Dezavantajele acestui preparat derivă din protocolul complicat de obţinerea şi utilizarea suplimentară a substanțelor cu rol anticoagulant şi de activare (16). Sângele este recoltat împreună cu agentul anticoagulant, centrifugat de 2 ori şi apoi necesită un aditiv suplimentar pentru activare. De asemenea, originea acestor aditivi reprezintă un dezavantaj major al PRP. Cel mai adesea, atât substanţa anticoagulantă, cât şi activatorul sunt de origine animală sau sintetică, putând duce la probleme de natură etică, răspunsuri imune nedorite din cauza provenienței lor sau pot compromite eficiența biologică a PRP (16).

De asemenea, preparatul este rapid resorbit de la nivelul locului de aplicare (în aproximativ 5 zile) şi eliberează aproape întreaga cantitate de factori de creştere conţinuţi în 6-8 minute după aplicare (17).

b. Din cauza dezavantajelor mai sus menționate, cercetările s-au concentrat pe obținerea unei formule îmbunătățite a preparatelor plachetare. Astfel, a apărut platelet-rich fibrin (PRF), preparat considerat ca făcând parte din a doua generație de concentrate plachetare. PRF a fost dezvoltat de Choukroun et al. (18). Aceeaşi echipă de cercetători a introdus mai târziu o nouă variantă a concentratelor plachetare, denumită A-PRF (advancedPRF), care are un conținut crescut de monocite (19).

Pentru obținerea PRF, sângele se recoltează fără niciun fel de aditivi şi este imediat centrifugat. De asemenea, substanțele pentru activare nu mai sunt necesare, deoarece se obține un cheag de fibrină prin polimerizare naturală. Protocolul simplificat rezultă în scurtarea timpului necesar intervenției, în comparație cu PRP (20). Cercetări multiple au ajuns la concluzia că PRF susţine o eliberare prelungită de factori de creştere (10-14 zile), cu canti- 
tatea maximă eliberată în ziua 7 postoperator $(20,21)$. Produsul reprezintă o matrice puternică, înalt organizată de fibrină, cu un conținut abundent de celule (plachete sangvine şi leucocite). Unul dintre principalele avantaje ale PRF este posibilitatea comprimării cheagului de fibrină şi transformării acestuia într-o membrană rezistentă (22).

PRF (de asemenea denumit şi L-PRF - leucocyte- and platelet-rich fibrin) conţine în plus şi numeroase celule imunitare, cu rol important în procesul de vindecare (15). Mai mult, din moment ce leucocitele (în special neutrofile şi macrofage) sunt printre primele celule recrutate la locul unei injurii, prin capacitatea lor de fagocitoză (detritusuri, microorganisme, țesut necrotic), acestea au rol în protecția împotriva infecțiilor la nivel local. Macrofagele, celule derivate din linia mieloidă, sunt decisiv implicate în secreția de factori de creştere în procesul de vindecare (TGF $\beta$, PDGF, VEGF). Efectele combinate ale plachetelor sangvine, neutrofilelor şi macrofagelor se reflectă în capacitatea acestui preparat de a induce regenerare tisulară, angiogeneză şi de a preveni infecțiile (20,23-25). Atât PRF, cât şi formulele mai noi (A-PRF) au demonstrat, in vitro, capacitatea de eliberare de niveluri mult ridicate de factori de creştere, în comparație cu vechile preparate (PRP), când s-a făcut dozarea acestora pe o perioadă de 10 zile (21).

\section{Efectele biologice ale derivatelor plachetare autologe}

După cum s-a menționat anterior, procesul de vindecare este un fenomen complex care implică intensificarea proliferării, adeziunii şi migrării țesutului conjunctiv şi a celulelor epiteliale, reacții inflamatorii şi remodelarea matricii extracelulare (26). Toate acestea sunt coordonate şi reglate de factori de creştere. Plachetele sangvine conțin granule cu astfel de molecule, inclusiv trei izomeri ai PDGF (AA, BB şi AB), două forme ale TGF (beta1 şi beta2), VEGF, factor de creştere fibroblastică (basic FGF-2) şi factor de creştere epidermală. PRP conţine, de asemenea, compuşi precum fibrina, fibronectina şi vitronectina, care modulează activitatea biologică pe perioada vindecării (27).

Studii in vitro au demonstrat abilitatea derivatelor plachetare autologe de a îmbunătăți procesul de vindecare prin modularea mecanismelor biologice la nivel molecular şi celular. În timpul formării cheagului, PDGF este eliberat din trombocite în urma degranulării acestora şi este implicat în fazele iniţiale ale procesului de reparație (26). Acest factor de creştere stimulează proliferarea celulară la concentrații fiziologice de $0,1-1 \mathrm{ng} / \mathrm{l}$, iar acest răspuns poate fi augmentat prin crosstalk cu integrina avb3 (28). PDGF are, de asemenea, efect chemotactic pentru diferite tipuri celulare, inclusiv monocite, fibroblaste gingivale şi celulele ligamentului parodontal (29).

Cercetările au demonstrat că PRP induce proliferarea şi migrarea fibroblastică $(30,31)$. Unele studii au ajuns la concluzia că atât PRP, cât şi PRF influențează pozitiv activitatea tuturor tipurilor celulare implicate în regenerarea parodontală: fibroblaste, osteoblaste (32-34) şi celulele ligamentului parodontal (35). Pe de altă parte, unele publicații nu au reuşit să demonstreze efectul adițional al derivatelor plachetare asupra formării de țesuturi dure (31).

Derivatele plachetare autologe conțin factor mitogenic atât pentru celulele stem mezenchimale provenite din măduva osoasă, cât şi pentru celule deja diferențiate (osteoblaste, fibroblaste gingivale şi celulele ligamentului parodontal). Acest efect este însă dependent de doză, iar o concentrație maximă nu este neapărat asociată cu cele mai bune rezultate. Astfel, cercetări ulterioare sunt necesare pentru a se stabili concentrația optimă de derivate plachetare necesară pentru inducerea regenerării tisulare. Utilizarea PRP pare să fie benefică prin îmbunătătirea vindecării plăgilor mucoasei orale şi gingivale (36).

Prin eliberarea de cantități crescute de VEGF, ambele tipuri de derivate plachetare (PRP şi PRF) induc neoformarea de capilare la 3 zile după aplicare şi, consecutiv, cresc numărul de vase sangvine mature, având astfel un puternic potențial angiogenic (37).

Efectele derivatelor plachetare au fost testate şi în relaţie cu unele microorganisme. PRP a inhibat creşterea unor parodontopatogeni recunoscuți precum Porphyromonas gingivalis şi Aggregatibacter actinomycetemcomitans (38).

Osteomielita este o complicație destul de frecventă după extracția molarilor de minte (aprox 9,5\% dintre cazuri). Prin aplicarea unui dop de PRF în situsul postextracțional, frecvența acestei complicații s-a redus semnificativ, ajungând la un pro- 
cent de $1 \%$ din cazuri (39). În ciuda acestor dovezi, proprietățile antibacteriene ale PRF sunt încă puțin cunoscute, deoarece puține cercetări au investigat acest fenomen (40).

\section{Efectele clinice ale derivatelor plachetare autologe}

Efectul aplicării derivatelor plachetare autologe a fost testat în diferite proceduri din sfera chirurgiei orale. Utilizarea acestui tip de preparate s-a dovedit a fi benefică în prezervarea alveolară postextracțională, prin îmunătățirea vindecării şi prin promovarea regenerării osoase (41). Cercetările conduse în domeniul implantologiei orale au adus, de asemenea, rezultate promiţătoare ale utilizării PRP/PRF. Combinarea derivatului plachetar cu diverse biomateriale s-a dovedit a fi utilizată cu succes în procedurile de elevare sinusală (42), în tratarea leziunilor de furcație şi a defectelor infraosoase parodontale (43). Alte aplicații includ procedurile de acoperire a retracțiilor gingivale (prin utilizarea împreună cu lamboul deplasat coronar) (44) şi în prezervarea alveolară postextracțională (45).

\section{MATERIAL ŞI METODĂ}

Review-ul de față şi-a propus obținerea unor informații legate de eficiența clinică a derivatelor plachetare autologe în tratamentul defectelor parodontale infraosoase. S-a realizat o căutare electronică a tuturor trialurile clinice randomizate (TCR) publicate în baza de date MEDLINE (căutate prin intermediul platformei PubMed) şi, de asemenea, s-a efectuat o căutare manuală în jurnale de referință pentru domeniul parodontologiei: Journal of Periodontology, Journal of Clinical Periodontology, Journal of Periodontal Research, Periodontology 2000. Pentru analiza de față, au fost luate în considerare TCR cu design de tip split-mouth sau cu grupuri paralele, având următoarele caracteristici: un grup experimental tratat cu derivate plachetare autologe (tratament unic sau combinații cu alte proceduri regeneratoare) şi un grup control (având aceeaşi abordare terapeutică, dar fără derivatul plachetar), pacienții incluşi să fie fără patologie generală care interferă cu terapia parodontală, dimensiuni inițiale ale defectelor parodontale de $\mathrm{CAL} \geq 4 \mathrm{~mm}$ (clinical attachment level; nivel clinic de ataşament) şi $P D \geq 3 \mathrm{~mm}$ (probing depth; adân- cime la sondare), fără implicarea zonei aplicale, CAL considerată variabilă principală de interes, periodă de urmărire de minimum 6 luni. Acuratețea metodologică a studiilor a fost evaluată luând în considerare următoarele aspecte: metoda de randomizare, aplicarea unui procedeu de mascare a metodei de tratament, alocată față de pacienți şi de examinatori, comparabilitatea grupurilor la momentul inițial, calcularea mărimii eşantionului, formularea clară a criteriilor de includere şi excludere în studiu, erorile din protocolul statistic.

După aplicarea strategiei de selecție menționate, din totalul de 100 de TCR, doar 19 au fost selectate pentru analiza rezultatelor. Tabelul 1 conține informaţii generale ale studiilor incluse şi gruparea acestora în funcție de procedura regeneratoare evaluată.

\section{DISCUŢII}

Majoritatea TCR analizate au ajuns la concluzia că utilizarea adițională a PRP alături de substitute osoase duce la rezultate statistic semnificativ mai bune în termeni de câştig de ataşament şi reducere a profunzimii pungilor, în comparație cu aplicarea doar a substitutului osos (51-59). Pe de altă parte, aplicarea PRP alături de substitutele osoase în regenerarea tisulară ghidată a fost, în general, asociată cu o lipsă de semnificație statistică în ceea ce priveşte îmbunătățirea rezultatelor clinic-radiologice, în tratamentul defectelor parodontale infraosoase (60-64). Totuşi, tratamentul experimental a fost raportat ca fiind superior în unele cercetări (60). Îmbunătățirea parametrilor țesutului dur (evaluați radiologic) prin adăugarea derivatului plachetar a fost inconstant observată în studiile selectate (5159).

Utilizarea PRF în terapia defectelor parodontale infraosoase tratate prin tehnici cu lambou a adus îmbunătățiri statistic semnificative, din punct de vedere clinic şi imagistic, în comparație cu lamboul de asanare fără derivat plachetar $(46,47)$.

PRF a fost utilizat şi ca membrană de acoperire peste defecte parodontale umplute cu substitute osoase. Rezultatele au fost statistic semnificativ mai bune, în termeni de CAL şi umplere osoasă, comparativ cu grefa osoasă simplă $(48,49)$.

O altă variantă de utilizare a derivatului plachetar în terapia defectelor infraosoase este compacta- 
TABELUL 1. Caracteristicile trialurilor clinice randomizate incluse în analiză

\begin{tabular}{|c|c|c|c|c|c|c|c|}
\hline Referință & Design studiu & $\begin{array}{l}\text { Mărime } \\
\text { eşantion }\end{array}$ & $\begin{array}{c}\text { Număr de pereți } \\
\text { ai defectelor } \\
\text { infraosoase }\end{array}$ & $\begin{array}{c}\text { Grup } \\
\text { experimental }\end{array}$ & Grup control & $\begin{array}{l}\text { Durata de } \\
\text { urmărire a } \\
\text { subiecților }\end{array}$ & $\begin{array}{l}\text { Procedura } \\
\text { regenerativă } \\
\text { testată }\end{array}$ \\
\hline$(46)$ & $\begin{array}{l}\text { grupuri } \\
\text { paralele }\end{array}$ & 32 situsuri & $2 / 3$ & PRF + OFD & OFD & 9 luni & \multirow{2}{*}{$P R F+O F D$} \\
\hline (47) & split-mouth & $\begin{array}{l}26 \text { situsuri } \\
\text { (13) }\end{array}$ & 3 & $P R F+O F D$ & OFD & 12 luni & \\
\hline (48) & split-mouth & $\begin{array}{c}42 \text { situsuri } \\
(21)\end{array}$ & $2 / 3$ & $P R F+B D X$ & BDX & 6 luni & \multirow{2}{*}{$\begin{array}{c}\text { PRF } \\
\text { (membrană) + } \\
\text { substitut osos }\end{array}$} \\
\hline (49) & split-mouth & $\begin{array}{c}20 \text { situsuri } \\
(10)\end{array}$ & $2 / 3$ & $\begin{array}{l}\text { PRF + sticlă } \\
\text { bioactivă }\end{array}$ & Sticlă bioactivă & 9 luni & \\
\hline (50) & split-mouth & $\begin{array}{l}36 \text { situsuri } \\
\text { (18) }\end{array}$ & 3 & $P R F+R T G$ & RTG & 9 luni & $\begin{array}{c}\text { PRF (material } \\
\text { de grefat) + RTG }\end{array}$ \\
\hline (51) & $\begin{array}{l}\text { grupuri } \\
\text { paralele }\end{array}$ & 60 situsuri & $2 / 3$ & PRP + DFDBA & DFDBA & 12 luni & \multirow{9}{*}{$\begin{array}{c}\text { PRP + substitut } \\
\text { osos }\end{array}$} \\
\hline$(52)$ & split-mouth & $\begin{array}{l}48 \text { situsuri } \\
\text { (24) }\end{array}$ & $1 / 2$ & PRP + DFDBA & DFDBA & 12 luni & \\
\hline (53) & split-mouth & $\begin{array}{c}26 \text { situsuri } \\
\text { (13) }\end{array}$ & $2 / 3$ & $P R P+B D X$ & BDX & 6 luni & \\
\hline (54) & $\begin{array}{l}\text { grupuri } \\
\text { paralele }\end{array}$ & 30 situsuri & $1 / 2$ & $P R P+B D X$ & BDX & 12 luni & \\
\hline (55) & $\begin{array}{l}\text { grupuri } \\
\text { paralele }\end{array}$ & 70 situsuri & $1 / 2 / 3$ & $\mathrm{PRP}+\mathrm{HA}$ & $\mathrm{HA}$ & 12 luni & \\
\hline$(56)$ & split-mouth & $\begin{array}{c}20 \text { situsuri } \\
(10)\end{array}$ & $2 / 3$ & $\begin{array}{c}\mathrm{PRP}+\mathrm{HA}+ \\
\text { betaTCP }\end{array}$ & $\mathrm{HA}+$ betaTCP & 6 luni & \\
\hline (57) & split-mouth & $\begin{array}{l}40 \text { situsuri } \\
(20)\end{array}$ & - & $\mathrm{PRP}+$ betaTCP & betaTCP & $\begin{array}{l}\text { 〜 luni (36 } \\
\text { săptămâni) }\end{array}$ & \\
\hline (58) & split-mouth & $\begin{array}{l}28 \text { situsuri } \\
\text { (14) }\end{array}$ & 3 & PRP + betaTCP & betaTCP & 6 luni & \\
\hline (59) & $\begin{array}{l}\text { grupuri } \\
\text { paralele }\end{array}$ & 29 situsuri & $1 / 2 / 3$ & $\begin{array}{l}\text { PRP + sticlă } \\
\text { bioactivă }\end{array}$ & Sticlă bioactivă & 9 luni & \\
\hline (60) & split-mouth & $\begin{array}{l}24 \text { situsuri } \\
\text { (12) }\end{array}$ & 2 & $\begin{array}{c}\text { PRP + os autolog } \\
\text { din torus } \\
\text { mandibular + RTG }\end{array}$ & $\begin{array}{c}\text { os autolog din } \\
\text { torus mandibular } \\
+ \text { RTG }\end{array}$ & 12 luni & \multirow{5}{*}{$\begin{array}{c}\text { PRP + substitut } \\
\text { osos + RTG }\end{array}$} \\
\hline (61) & $\begin{array}{l}\text { grupuri } \\
\text { paralele }\end{array}$ & 30 situsuri & $1 / 2 / 3$ & $\mathrm{PRP}+\mathrm{BDX}+\mathrm{RTG}$ & $\mathrm{BDX}+\mathrm{RTG}$ & 12 luni & \\
\hline$(62)$ & $\begin{array}{l}\text { grupuri } \\
\text { paralele }\end{array}$ & 24 situsuri & $1 / 2$ & $P R P+B D X+R T G$ & $B D X+R T G$ & 12 luni & \\
\hline (63) & split-mouth & $\begin{array}{c}46 \text { situsuri } \\
(23)\end{array}$ & $2 / 3$ & $P R P+B D X+R T G$ & $B D X+R T G$ & 6 luni & \\
\hline (64) & $\begin{array}{l}\text { grupuri } \\
\text { paralele }\end{array}$ & 28 situsuri & $1 / 2 / 3$ & $\begin{array}{c}\text { PRP + betaTCP + } \\
\text { RTG }\end{array}$ & betaTCP + RTG & 12 luni & \\
\hline
\end{tabular}

rea PRF-ului în defect şi acoperirea acestuia cu o membrană în tehnica RTG. Rezultatele studiilor care au cercetat această abordare terapeutică au arătat îmbunătățiri semnificativ mai importante ale tuturor parametrilor studiați (câştig de ataşament, reducere a profunzimii pungilor, umplere osoasă decelabilă radiologic), în comparație cu RTG fără PRF (50).

Studiile sus-menționate au fost incluse şi analizate în review-uri sistematice şi meta-analize, ale căror concluzii generale confirmă rezultatele cerce- tărilor individuale şi susțin utilitatea derivatelor plachetare autologe (PRP/PRF) în terapia regeneratoare a defectelor infraosoase parodontale $(65,66)$. Derivatele plachetare autologe aduc un beneficiu suplimentar atunci când sunt utilizate alături de substitutele osoase în tratamentul defectelor infraosoase $(67,68)$.

Concentratele plachetare utilizate în procedurile parodontale regeneratoare nu aduc îmbunătăţiri ale parametrilor clinico-radiologici, când sunt combinate cu RTG (67-69). Totuşi, unele analize au con- 
cluzionat că adăugarea PRP în RTG are un efect benefic asupra rezultatelor tratamentului (70).

PRF s-a demonstrat a fi eficient ca material unic de regenerare, ducând la rezultate superioare față de cele obținute prin tratamentul defectelor infraosoase doar cu lambou de asanare $(46,47,50,69)$.

Utilizarea derivatelor plachetare autologe promovează vindecarea şi regenerarea țesuturilor moi şi reduce disconfortul postoperator, dar cercetări ulterioare sunt necesare pentru a valida utilitatea acestor preparate în obținerea regenerării osoase $(13,22,40)$.

Rezultatele furnizate de toate aceste analize privind eficiența clinică a derivatelor plachetare trebuie însă interpretate cu precauție din cauza heterogenității studiilor analizate.

Una dintre cauze a fost varietatea protocoalelor aplicate pentru obținerea preparatului autolog, fapt care duce la produse cu caracteristici diferite. Numeroase studii au demonstrat că proprietăţile mecanice şi biologice ale derivatelor plachetare sunt influențate de modul de recoltare al sângelui, parametrii de centrifugare, metoda de activare a produsului şi modul de utilizare propriu-zis. Pentru a exista comparabilitate între rezultatele cercetărilor, este nevoie de o uniformizare şi standardizare a protocoalelor de obținere a derivatelor plachetare autologe (48).

Un alt aspect care împiedică trasarea unor concluzii clare a fost combinarea concentratelor plachetare $\mathrm{cu}$ biomateriale pentru care regenerarea parodontală a fost deja demonstrată. Efectul benefic al preparatelor experimentale a fost probabil mascat de eficiența dovedită a celorlalte materiale utilizate.

Mai mult, în unele dintre studii nu s-a efectuat un control riguros al igienei orale a subiecților incluşi, raportându-se diferențe statistic semnificative între indicii de igienă orală în diferite momente ale studiului. Este foarte bine cunoscut faptul că rezultatele terapiei parodontale sunt înalt dependente de igiena orală a pacientului. Instruirea şi motivarea subiecților în legătură cu metodele de igienizare ar trebui făcute înainte de aplicarea terapiei regeneratoare şi pe întreg parcursul perioadei de urmărire (56).

Heterogenitatea rezultatelor studiilor incluse poate fi şi o consecinţă a perioadei scurte de urmărire a subiecților. Doar 9 dintre cele 19 publicații analizate au atins pragul de 12 luni de follow-up.
Cercetări cu perioade de evaluare mai lungi trebuie conduse pentru a verifica stabilitatea rezultatelor în timp şi pentru a obține posibile diferențe statistic semnificative între grupuri $(48,62)$.

Rezultatele terapiei parodontale regenerative au fost cuantificate prin markeri surogat (CAL, PD şi umplerea osoasă), în timp ce singura metodă care determină exact natura țesuturilor nou formate şi efectul tratamentului este analiza histologică. Aceasta a fost însă imposibil de efectuat în studiile clinice conduse (53).

$\mathrm{Nu}$ în ultimul rând, nu trebuie ignorat faptul că parametrii evaluați de pacient au fost raportați întrun singur studiu dintre cele 19 incluse în analiză (47). Chiar dacă aceste rezultate par să nu fie semnificative în evaluarea potențialului regenerator al derivatelor plachetare autologe, utilizarea adițională a acestor preparate poate să fie benefică pentru creşterea complianței pacienților la tratament (scăderea disconfortului postoperator, vindecare mai rapidă şi mai eficientă, rezultate mai bune din punct de vedere estetic) în comparație cu alte abordări regenerative.

\section{CONCLUZII}

Datele existente în literatură indică un beneficiu adițional în termeni clinico-radiologici al utilizării derivatelor plachetare (PRP, PRF) în terapia regenerativă a defectelor infraosoase parodontale, fie prin utilizarea lor singulară sau prin combinarea cu substitute osoase.

Rezultate inconstante au fost raportate în cazul aplicării PRP împreună cu RTG.

PRF s-a dovedit a fi mai eficient în tratamentul defectelor infraosoase, în comparație cu lamboul de asanare.

Heterogenitatea studiilor incluse nu permite trasarea unor concluzii mai precise. Există limitări ale stadiului actual al cunoaşterii pe această temă.

Standardizarea protocoalelor de obținere şi manipulare a derivatelor plachetare autologe este obligatorie pentru observarea efectelor acestor preparate în trialuri clinice.

Mulțumiri. Această lucrare a fost realizată în cadrul Proiectului de Cercetare Doctorală susținut de Universitatea de Medicină şi Farmacie „Iuliu Hațieganu“, Cluj-Napoca, nr. contract 1680/49 din 19.01.2018. 


\section{BIBLIOGRAFIE}

1. Papapanou PN, Sanz M, Buduneli N, Dietrich T, Feres M, Fine DH et al. Periodontitis: Consensus report of workgroup 2 of the 2017 World Workshop on the Classification of Periodontal and Peri-Implant Diseases and Conditions: Classification and case definitions for periodontitis. Journal of Clinical Periodontology. 2018 Jun;45:S162-70.

2. Kao RT, Nares S, Reynolds MA. Periodontal Regeneration - Intrabony Defects: A Systematic Review From the AAP Regeneration Workshop. Journal of Periodontology. 2015 Feb;86(2-s):S77-104.

3. Larsson L, Decker AM, Nibali L, Pilipchuk SP, Berglundh T, Giannobile WV. Regenerative Medicine for Periodontal and Peri-implant Diseases. Journal of Dental Research. 2016 Mar;95(3):255-66.

4. Reynolds MA, Kao RT, Camargo PM, Caton JG, Clem DS, Fiorellini JP et al. Periodontal Regeneration - Intrabony Defects: A Consensus Report From the AAP Regeneration Workshop. Journal of Periodontology. 2015 Feb;86(2s):S105-7.

5. Sculean A, Nikolidakis D, Nikou G, Ivanovic A, Chapple ILC, Stavropoulos A. Biomaterials for promoting periodontal regeneration in human intrabony defects: A systematic review. Periodontology 2000. 2015 Jun;68(1):182-216.

6. Guo S, Dipietro LA. Factors affecting wound healing. J Dent Res. 2010 Mar;89(3):219-29.

7. Gosain A, DiPietro LA. Aging and Wound Healing. World Journal of Surgery. 2004 Mar 1;28(3):321-6.

8. Stoecklin-Wasmer C, Rutjes AWS, da Costa BR, Salvi GE, Jüni P, Sculean A. Absorbable Collagen Membranes for Periodontal Regeneration: A Systematic Review. Journal of Dental Research. 2013 Sep;92(9):773-81.

9. Murphy K, Gunsolley J. Guided tissue regeneration for the treatment of periodontal intrabony and furcation defects. Annals of Periodontology. 2003 Dec;8(1):266-302.

10. Parodi R, Carusi G, Santarelli G, Nanni F, Pingitore R, Brunel G. Guided tissue regeneration employing a collagen membrane in a human periodontal bone defect: A histological evaluation. International Journal of Periodontics and Restorative Dentistry. 1997 Jun;17(3):282-91.

11. Nurden A. Platelets, inflammation and tissue regeneration. Thrombosis and Haemostasis. 2011;105(S 06):S13-33.

12. Dohan Ehrenfest DM, Rasmusson L, Albrektsson T. Classification of platelet concentrates: From pure platelet-rich plasma (P-PRP) to leucocyte- and platelet-rich fibrin (L-PRF). Trends in Biotechnology. 2009 Mar;27(3):158-67.

13. Miron RJ, Zucchelli G, Pikos MA, Salama M, Lee S, Guillemette $V$ et al. Use of platelet-rich fibrin in regenerative dentistry: A systematic review. Clinical Oral Investigations. 2017 Jul;21(6):1913-27.

14. Peerbooms JC, van Laar W, Faber F, Schuller HM, van der Hoeven $\mathrm{H}$, Gosens $\mathrm{T}$. Use of platelet rich plasma to treat plantar fasciitis: Design of a multi centre randomized controlled trial. BMC Musculoskelet Disord. $2010 \mathrm{Apr}$ 14;11:69.

15. Davis VL, Abukabda AB, Radio NM, Witt-Enderby PA, Clafshenkel WP, Cairone JV et al. Platelet-Rich Preparations to Improve Healing. Part I: Workable Options for Every Size Practice. Journal of Oral Implantology. 2014 Aug;40(4):50010.

16. Agrawal AA. Evolution, current status and advances in application of platelet concentrate in periodontics and implantology. World Journal of Clinical Cases. 2017;5(5):159.

17. Dohan Ehrenfest DM, Bielecki T, Jimbo R, Barbé G, Del Corso $\mathrm{M}$, Inchingolo $\mathrm{F}$ et al. Do the fibrin architecture and leukocyte content influence the growth factor release of platelet concentrates? An evidence-based answer comparing a pure platelet-rich plasma (P-PRP) gel and a leukocyte- and platelet-rich fibrin (L-PRF). Curr Pharm Biotechnol. 2012 Jun;13(7):1145-52.

18. Choukroun J, Adda F, Shoeffer C, Vervelle A. PRF: An opportunity in perio implantology. Implantodontie. 2000;42:55-62.

19. Choukroun J. Advanced PRF and i-PRF: Platelet concentrate or blood concentrate? Journal of Periodontal Medicine and Clinical Practice. 2014;1:3.

20. Dohan DM, Choukroun J, Diss A, Dohan SL, Dohan AJJ, Mouhyi J et al. Platelet-rich fibrin (PRF): A second-generation platelet concentrate. Part II: platelet-related biologic features. Oral Surg Oral Med Oral Pathol Oral Radiol Endod. 2006 Mar;101(3):e45-50.

21. Kobayashi E, Flückiger L, Fujioka-Kobayashi M, Sawada K, Sculean A, Schaller B et al. Comparative release of growth factors from PRP, PRF, and advanced-PRF. Clin Oral Investig. 2016 Dec;20(9):2353-60.

22. Castro AB, Meschi N, Temmerman A, Pinto N, Lambrechts $P$, Teughels $W$ et al. Regenerative potential of leucocyte- and platelet-rich fibrin. Part A: intra-bony defects, furcation defects and periodontal plastic surgery. A systematic review and meta-analysis. Journal of Clinical Periodontology. 2017 Jan;44(1):67-82.

23. Choukroun J, Diss A, Simonpieri A, Girard M-O, Schoeffler C, Dohan SL et al. Platelet-rich fibrin (PRF): A secondgeneration platelet concentrate. Part IV: clinical effects on tissue healing. Oral Surg Oral Med Oral Pathol Oral Radiol Endod. 2006 Mar;101(3):e56-60.

24. Dohan DM, Choukroun J, Diss A, Dohan SL, Dohan AJJ, Mouhyi $\mathrm{J}$ et al. Platelet-rich fibrin (PRF): A second-generation platelet concentrate. Part I: technological concepts and evolution. Oral Surg Oral Med Oral Pathol Oral Radiol Endod. 2006 Mar;101(3):e37-44.

25. Dohan DM, Choukroun J, Diss A, Dohan SL, Dohan AJJ, Mouhyi J et al. Platelet-rich fibrin (PRF): A second-generation platelet concentrate. Part III: Leucocyte activation: A new feature for platelet concentrates? Oral Surgery, Oral Medicine, Oral Pathology, Oral Radiology, and Endodontology. 2006 Mar;101(3):e51-5.

26. Smith PC, Martínez C, Cáceres M, Martínez J. Research on growth factors in periodontology. Periodontology 2000. 2015 Feb;67(1):234-50.

27. Andia I, Sánchez M, Maffulli N. Basic Science: Molecular and Biological Aspects of Platelet-Rich Plasma Therapies. Operative Techniques in Orthopaedics. 2012 Mar 1; 22(1):3-9.

28. Ray AK, Jones AC, Carnes DL, Cochran DL, Mellonig JT, Oates TW. Platelet-Derived Growth Factor-BB Stimulated Cell Migration Mediated Through p38 Signal Transduction Pathway in Periodontal Cells. Journal of Periodontology. 2003 Sep;74(9):1320-8.

29. Rönnstrand L, Heldin C. Mechanisms of platelet-derived growth factor-induced chemotaxis. International Journal of Cancer. 2001 Mar 15;91(6):757-62.

30. Anitua E, Troya M, Orive G. Plasma rich in growth factors promote gingival tissue regeneration by stimulating fibroblast proliferation and migration and by blocking transforming growth factor- $\beta 1$-induced myodifferentiation. J Periodontol. 2012 Aug;83(8):1028-37.

31. Kobayashi E, Fujioka-Kobayashi M, Sculean A, Chappuis V, Buser D, Schaller B et al. Effects of platelet rich plasma 
(PRP) on human gingival fibroblast, osteoblast and periodontal ligament cell behaviour. BMC Oral Health [Internet]. 2017 Dec [cited 2018 Apr 18];17(1). Available from: http://bmcoralhealth.biomedcentral.com/articles/10.1186/ s12903-017-0381-6

32. Anitua E, Tejero R, Zalduendo MM, Orive G. Plasma rich in growth factors promotes bone tissue regeneration by stimulating proliferation, migration, and autocrine secretion in primary human osteoblasts. J Periodontol. 2013 Aug;84(8):1180-90.

33. Dohan Ehrenfest DM, Diss A, Odin G, Doglioli P, Hippolyte M-P, Charrier J-B. In vitro effects of Choukroun's PRF (platelet-rich fibrin) on human gingival fibroblasts, dermal prekeratinocytes, preadipocytes, and maxillofacial osteoblasts in primary cultures. Oral Surg Oral Med Oral Pathol Oral Radiol Endod. 2009 Sep;108(3):341-52.

34. Graziani F, Ivanovski S, Cei S, Ducci F, Tonetti M, Gabriele $M$. The in vitro effect of different PRP concentrations on osteoblasts and fibroblasts. Clin Oral Implants Res. 2006 Apr;17(2):212-9.

35. Anitua E, Troya M, Orive G. An autologous platelet-rich plasma stimulates periodontal ligament regeneration. J Periodontol. 2013 Nov;84(11):1556-66.

36. Lindeboom JAH, Mathura KR, Aartman IHA, Kroon FHM, Milstein DMJ, Ince C. Influence of the application of plateletenriched plasma in oral mucosal wound healing. Clinical Oral Implants Research. 2007 Feb;18(1):133-9.

37. Kobayashi M, Kawase T, Okuda K, Wolff LF, Yoshie H. In vitro immunological and biological evaluations of the angiogenic potential of platelet-rich fibrin preparations: A standardized comparison with PRP preparations. International Journal of Implant Dentistry [Internet]. 2015 Dec [cited 2018 Apr 18];1(1). Available from: http://www.journalimplantdent.com/ content $/ 1 / 1 / 31$

38. Badade PS, Mahale SA, Panjwani AA, Vaidya PD, Warang $A D$. Antimicrobial effect of platelet-rich plasma and plateletrich fibrin. Indian J Dent Res. 2016 Jun;27(3):300-4.

39. Hoaglin DR, Lines GK. Prevention of Localized Osteitis in Mandibular Third-Molar Sites Using Platelet-Rich Fibrin. International Journal of Dentistry. 2013;2013:1-4.

40. Miron RJ, Fujioka-Kobayashi M, Bishara M, Zhang Y, Hernandez M, Choukroun J. Platelet-Rich Fibrin and Soft Tissue Wound Healing: A Systematic Review. Tissue Engineering Part B: Reviews. 2017 Feb;23(1):83-99.

41. Antonello G de M, Torres do Couto R, Giongo CC, Corrêa $M B$, Chagas Júnior OL, Lemes CHJ. Evaluation of the effects of the use of platelet-rich plasma (PRP) on alveolar bone repair following extraction of impacted third molars: Prospective study. J Craniomaxillofac Surg. 2013 Jun;41(4):e70-75.

42. Kanayama T, Horii K, Senga Y, Shibuya Y. Crestal Approach to Sinus Floor Elevation for Atrophic Maxilla Using PlateletRich Fibrin as the Only Grafting Material: A 1-Year Prospective Study. Implant Dent. 2016 Feb;25(1):32-8.

43. Albanese A, Licata ME, Polizzi B, Campisi G. Platelet-rich plasma (PRP) in dental and oral surgery: From the wound healing to bone regeneration. Immunity \& Ageing. 2013;10(1):23.

44. Jankovic S, Aleksic Z, Klokkevold P, Lekovic V, Dimitrijevic B, Kenney EB et al. Use of platelet-rich fibrin membrane following treatment of gingival recession: A randomized clinical trial. Int J Periodontics Restorative Dent. 2012 Apr;32(2):e41-50.

45. Temmerman A, Vandessel J, Castro A, Jacobs R, Teughels $\mathrm{W}$, Pinto $\mathrm{N}$ et al. The use of leucocyte and platelet-rich fibrin in socket management and ridge preservation: A split-mouth, randomized, controlled clinical trial. J Clin Periodontol. 2016 Nov;43(11):990-9.

46. Thorat M, Pradeep AR, Pallavi B. Clinical effect of autologous platelet-rich fibrin in the treatment of intra-bony defects: A controlled clinical trial. Platelet-rich fibrin and periodontal regeneration. Journal of Clinical Periodontology. 2011 Oct;38(10):925-32.

47. Patel GK, Gaekwad SS, Gujjari SK, S.C. VK. Platelet-Rich Fibrin in Regeneration of Intrabony Defects: A Randomized Controlled Trial. Journal of Periodontology. 2017 Nov;88(11):1192-9.

48. Sezgin Y, Uraz A, Taner IL, çUlhaoğLu R, Başkent University, Turkey, Gazi University, Turkey. Effects of platelet-rich fibrin on healing of intra-bony defects treated with anorganic bovine bone mineral. Brazilian Oral Research [Internet]. 2017 [cited 2018 Apr 18];31(0). Available from: http://www.scielo.br/ scielo.php?script=sci_arttext\&pid=S1806$83242017000100213 \&$ Ing=en\&tlng=en

49. Naqvi A. Comparative Evaluation of Bioactive Glass Putty and Platelet Rich Fibrin in the Treatment of Human Periodontal Intrabony Defects: A Randomized Control Trial. JOURNAL OF CLINICAL AND DIAGNOSTIC RESEARCH [Internet]. 2017 [cited 2018 Apr 18]; Available from: http://jcdr. net/article_fulltext.asp?issn=0973-709x\&year=2017\&volume= 11\&issue=7\&page=ZC09\&issn=0973-709x\&id=10149

50. Panda S, Sankari M, Satpathy A, Jayakumar D, Mozzati M, Mortellaro C et al. Adjunctive Effect of Autologus Platelet-Rich Fibrin to Barrier Membrane in the Treatment of Periodontal Intrabony Defects. J Craniofac Surg. 2016 May;27(3):691-6.

51. Piemontese M, Aspriello SD, Rubini C, Ferrante L, Procaccini $M$. Treatment of periodontal intrabony defects with demineralized freeze-dried bone allograft in combination with platelet-rich plasma: A comparative clinical trial. J Periodontol. 2008 May;79(5):802-10.

52. Agarwal A, Gupta ND. Platelet-Rich Plasma Combined with Decalcified Freeze-Dried Bone Allograft for the Treatment of Noncontained Human Intrabony Periodontal Defects: A Randomized Controlled Split-Mouth Study. Restorative Dentistry. 2014;34(5):8.

53. Hanna R, Trejo PM, Weltman RL. Treatment of Intrabony Defects With Bovine-Derived Xenograft Alone and in Combination With Platelet-Rich Plasma: A Randomized Clinical Trial. Journal of Periodontology. 2004 Dec;75(12):1668-77.

54. Döri F, Kovács V, Arweiler NB, Huszár T, Gera I, Nikolidakis D et al. Effect of platelet-rich plasma on the healing of intrabony defects treated with an anorganic bovine bone mineral: A pilot study. J Periodontol. 2009 Oct;80(10):1599-605.

55. Okuda K, Tai H, Tanabe K, Suzuki H, Sato T, Kawase T et al. Platelet-Rich Plasma Combined With a Porous Hydroxyapatite Graft for the Treatment of Intrabony Periodontal Defects in Humans: A Comparative Controlled Clinical Study. Journal of Periodontology. 2005 Jun;76(6):890-8.

56. Kaushick BT, Jayakumar ND, Padmalatha O, Varghese S. Treatment of human periodontal infrabony defects with hydroxyapatite $+\beta$ tricalcium phosphate bone graft alone and in combination with platelet rich plasma: A randomized clinical trial. Indian J Dent Res. 2011 Aug;22(4):505-10.

57. Saini N, Sikri P, Gupta H. Evaluation of the relative efficacy of autologous platelet-rich plasma in combination with $\beta$-tricalcium phosphate alloplast versus an alloplast alone in the treatment of human periodontal infrabony defects: $A$ clinical and radiological study. Indian J Dent Res. 2011 Feb;22(1):107-15.

58. Ozdemir B, Okte E. Treatment of intrabony defects with beta-tricalciumphosphate alone and in combination with 
platelet-rich plasma. J Biomed Mater Res Part B Appl Biomater. 2012 May;100(4):976-83.

59. Demir B, Şengün D, Berberoğlu A. Clinical evaluation of platelet-rich plasma and bioactive glass in the treatment of intra-bony defects. Journal of Clinical Periodontology. 2007 Aug;34(8):709-15.

60. Hassan KS, Alagl AS, Abdel-Hady A. Torus mandibularis bone chips combined with platelet rich plasma gel for treatment of intrabony osseous defects: Clinical and radiographic evaluation. International Journal of Oral and Maxillofacial Surgery. 2012 Dec;41(12):1519-26.

61. Döri F, Huszár T, Nikolidakis D, Arweiler NB, Gera I, Sculean A. Effect of platelet-rich plasma on the healing of intra-bony defects treated with a natural bone mineral and a collagen membrane. Journal of Clinical Periodontology. 2007 Mar;34(3):254-61.

62. Döri F, Huszár T, Nikolidakis D, Arweiler NB, Gera I, Sculean A. Effect of platelet-rich plasma on the healing of intrabony defects treated with an anorganic bovine bone mineral and expanded polytetrafluoroethylene membranes. J Periodontol. 2007 Jun;78(6):983-90.

63. Camargo PM, Lekovic V, Weinlaender M, Divnic-Resnik T, Pavlovic M, Kenney EB. A Surgical Reentry Study on the Influence of Platelet-Rich Plasma in Enhancing the Regenerative Effects of Bovine Porous Bone Mineral and Guided Tissue Regeneration in the Treatment of Intrabony Defects in Humans. Journal of Periodontology. 2009 Jun;80(6):915-23.

64. Döri F, Huszár T, Nikolidakis D, Tihanyi D, Horváth A, Arweiler NB et al. Effect of platelet-rich plasma on the healing of intrabony defects treated with Beta tricalcium phosphate and expanded polytetrafluoroethylene membranes. J Periodontol. 2008 Apr;79(4):660-9.
65. Plachokova AS, Nikolidakis D, Mulder J, Jansen JA, Creugers NHJ. Effect of platelet-rich plasma on bone regeneration in dentistry: A systematic review. Clin Oral Implants Res. 2008 Jun;19(6):539-45.

66. Kotsovilis S, Markou N, Pepelassi E, Nikolidakis D. The adjunctive use of platelet-rich plasma in the therapy of periodontal intraosseous defects: A systematic review. J Periodont Res. 2010 Jun;45(3):428-43.

67. Del Fabbro M, Bortolin M, Taschieri S, Weinstein R. Is platelet concentrate advantageous for the surgical treatment of periodontal diseases? A systematic review and metaanalysis. J Periodontol. 2011 Aug;82(8):1100-11.

68. Hou X, Yuan J, Aisaiti A, Liu Y, Zhao J. The effect of plateletrich plasma on clinical outcomes of the surgical treatment of periodontal intrabony defects: A systematic review and meta-analysis. BMC Oral Health [Internet]. 2016 Dec [cited 2018 Apr 18];16(1). Available from: http://bmcoralhealth. biomedcentral.com/articles/10.1186/s12903-016-0261-5

69. Shah M, Deshpande N, Bharwani A, Nadig P, Doshi V, Dave D. Effectiveness of autologous platelet-rich fibrin in the treatment of intra-bony defects: A systematic review and meta-analysis. J Indian Soc Periodontol. 2014 Dec;18(6):698-704.

70. Roselló-Camps À, Monje A, Lin G-H, Khoshkam V, ChávezGatty M, Wang H-L et al. Platelet-rich plasma for periodontal regeneration in the treatment of intrabony defects: $A$ meta-analysis on prospective clinical trials. Oral Surgery, Oral Medicine, Oral Pathology and Oral Radiology. 2015 Nov;120(5):562-74. 